\title{
COMENTARIOS A LOS PROYECTOS REFUNDIDOS EN MATERIA DE SOCIEDAD CONYUGAL (BOLETINES NoS. 5970-18, 7567-07 Y 7727-18)
}

\author{
COMMENTS TO CONSOLIDATED BILLS INTO MARITAL PROPERTY SYSTEM
}

(OfFicial Bulletins 5970-18, 7567-07 and 7727-18)

\section{COMMENTAIRE SUR LES PROJETS CONSOLIDÉS SUR LA SOCIÉTÉ CONJUGALE}

(Bulletins 5970-18, 7567-07 ET 7727-18)

\author{
MaUricio TAPIA RodríGUez ${ }^{* * *}$
}

Quisiera agradecer, a nombre propio y del Departamento de Derecho Privado de la Facultad de Derecho de la Universidad de Chile, que tengo el honor de dirigir, a los miembros de la Comisión de Constitución, Legislación y Justicia de la Cámara de Diputados, especialmente a su presidente, H. diputado don Cristián Monckeberg, quienes nos formularan esta invitación.

Hacemos presente que estos comentarios se refieren a los proyectos refundidos en materia de sociedad conyugal (Boletines $\mathrm{No}^{\circ}$. 5970-18, 7567-07 y 7727-18), que en adelante serán referidos en conjunto como los "Proyectos" y, en particular, al contenido en el Mensaje del Presidente de la República (Boletín No 7567-07), en adelante también denominado como el "Mensaje".

\section{ConteXtualización de la discusión}

La discusión sobre la reforma a la sociedad conyugal es un debate antiguo y vigente a la vez. Las modificaciones y perfeccionamientos propuestos a este régimen de bienes, se remontan al menos a la primera mitad del siglo XX. Sin perjuicio de varias modificaciones, a las que me referiré más adelante, existe un importante proyecto de modificación de la sociedad conyugal, contenido en el Boletín No 1707-18, y que corresponde a una propuesta en la que contribuyeron

\footnotetext{
* Comentarios expuestos por el autor en la sesión de la Comisión de Constitución, Legislación y Justicia de la Cámara de Diputados, de 15 de mayo de 2012, destinada a estudiar los proyectos refundidos en materia de sociedad conyugal (Boletines Nos. 5970-18, 7567-07 y 7727-18).

El profesor Mauricio Tapia agradece la colaboración en la preparación de estos comentarios de la profesora María Paz Gatica y del ayudante José Antonio Sánchez, pertenecientes al Departamento de Derecho Privado de la Facultad de Derecho de la Universidad de Chile.

** El artículo fue aprobado para su publicación el 20 de marzo de 2013.

*** Abogado. Licenciado en Ciencias Jurídicas y Sociales de la Universidad de Chile. Máster en Derecho Privado y Doctor (C) en Derecho Universidad Paris-Est Créteil Val de Marne, Francia. Profesor de Derecho Civil y Director del Departamento de Derecho Privado de la Facultad de Derecho, Universidad de Chile. Correo electrónico: mtapia@derecho.uchile.cl.
} 
destacados profesores de Derecho Civil. Dicho proyecto se discutió durante 10 años en esta Cámara de Diputados y, posteriormente, durante 3 años en el Senado. Ante todo, debo hacer presente a esta Comisión mi sorpresa, por el olvido de que fue objeto el proyecto al término del año 2008, sobre todo, considerando que en él se analizaron distintas alternativas para superar las críticas que se formulan a la sociedad conyugal (en particular, aquellas que se refieren a la desigualdad civil de la mujer), así como también se discutieron medidas para fortalecer la institución de los bienes familiares.

En opinión de este académico -y a diferencia de lo que señala el Mensaje, contenido en el Boletín No 7567-07, elaborado por el SERNAM- era posible, y deseable, dar una continuidad a ese debate parlamentario, contenido en el proyecto anterior que acabo de mencionar (Boletín No 1707-18), pues en su última etapa se discutía en gran medida lo que se quiere lograr con estos nuevos Proyectos. Por lo demás, por razones que este académico desconoce, los Proyectos en comento no abordan el fortalecimiento y perfeccionamiento de la institución de los bienes familiares, que sí eran tratados por el proyecto anterior, aprobado en primer trámite constitucional por esta Cámara de Diputados.

\section{Objetivos de estos Proyectos de Reforma}

Por tanto, la pregunta general que cabe hacerse al comenzar esta exposición, es la siguiente: ¿qué se quiere hacer hoy, mediante estos nuevos Proyectos de Reforma?

Si se examina el Mensaje (Boletín No 7567-07), la modificación legal propuesta persigue propósitos disímiles:

Ante todo, persigue la igualdad civil de la mujer al interior del matrimonio y, en particular, bajo el régimen de sociedad conyugal. Al respecto, se debe tener presente que existe un acuerdo de solución amistosa ante la Comisión Interamericana de Derechos Humanos (No 12.433), mediante el cual, el Estado de Chile se comprometió a reformar con urgencia el Código Civil para otorgar iguales derechos y obligaciones a la mujer y al marido al interior de la sociedad conyugal. Ese es un compromiso internacional, cuyo cumplimiento se encuentra pendiente, y resulta paradójico que el Mensaje ni siquiera haga referencia a ello. Cabe, por tanto, la pregunta de si estos Proyectos se elaboraron con miras a dar cumplimiento a ese compromiso internacional, o si persiguen otros propósitos.

Luego, cabe preguntarse también si mediante los Proyectos se quiere construir un nuevo régimen de bienes del matrimonio, o sólo modificar sustancialmente la sociedad conyugal. En efecto, se trata de dos preguntas distintas, pues se puede lograr la igualdad plena de la mujer al interior del matrimonio, sin crear un nuevo régimen de bienes. Ahora bien, aun cuando el Mensaje mantiene el nombre de sociedad conyugal, como expondré más adelante, las modificaciones que introduce en el régimen lo transforman sustancialmente, a un punto tal, que es pertinente 
preguntarse si, de aprobarse tales modificaciones, no se estaría creando un nuevo régimen de comunidad sumamente empobrecido (donde el patrimonio común, efectivamente, resulta gravemente disminuido, en perjuicio del núcleo familiar).

Por último, el Mensaje también declara abiertamente que su propósito es proteger al cónyuge que se ha dedicado al cuidado de los hijos y del hogar, o que ha trabajado en menor medida de lo que hubiese querido o podido por estas causas. En este punto, el Mensaje pretende incorporar nuevas protecciones, en un sentido similar a las ya existentes mediante la compensación económica (institución prevista en la actual Ley de Matrimonio Civil, bajo un concepto prácticamente idéntico al mencionado por el Mensaje).

De lo expuesto, se desprende que el Mensaje persigue en definitiva tres propósitos: la igualdad civil al interior del matrimonio, la protección reforzada del cónyuge débil y una intervención severa de los patrimonios de la sociedad conyugal, disminuyendo los bienes que se consideran comunes. Como se entiende, se trata de una gran confusión de propósitos y, como es sabido, cuando las leyes tienen objetivos diversos y poco claros presentan posteriormente graves problemas de aplicación.

\section{Funciones de las leyes CiVILES EN MATERIA DE FAMilia}

Para entender el sentido de una reforma en la materia, resulta necesario efectuar observaciones generales acerca de la función de las leyes civiles en materia de familias, que pueden resultar útiles al momento en que se legisla al respecto.

Algunas particularidades de las leyes civiles de familia parecen suficientes para mostrar esta función.

Las leyes de familia son tributarias de la historia, mutan con las costumbres de los pueblos. Por ello, debemos reconocer que, en la materia, el Código Civil no es el mismo que se dictó en el siglo XIX.

Es cierto, por lo demás, que las leyes civiles no son instrumentos vanguardistas, pues no anteceden a los cambios sociales. Las leyes civiles de familia son reflejo de un modo de vida ampliamente compartido, en un momento determinado. Las costumbres cambian lentamente, y las leyes sobre la materia se van modificando de forma gradual y prudente, pues son también instrumentos de seguridad jurídica.

Por otra parte, debe también tenerse presente que las leyes civiles de familia inciden sobre instituciones sociales, en las cuales confluyen distintas convicciones religiosas o aproximaciones filosóficas, como ocurre con la noción y el sentido del matrimonio, el rol de los hijos y de la mujer. De ahí también que todas las modificaciones legales en la materia siempre envuelvan compromisos o transacciones sociales reflejadas legislativamente. Por eso se ha dicho, con razón, que las leyes civiles de familia son instrumentos pacificadores.

Pero, en todo caso, las leyes civiles de familia no hacen más que reconocer ciertos consensos sociales, y no intentan, por ello, cambiar la realidad social (no 
tienen herramientas para lograrlo). No son instrumentos programáticos, sino que regulan las relaciones familiares que existen en la práctica, y no aquellas que ciertos grupos quieren que existan.

\section{Panorama de las Reformas civiles efectuadas y la PRECARIEDAD DE LA REGULACIÓN ACTUAL}

Si seguimos esta función, y estos principios, que inspiran las leyes civiles de familia, reflejos de la evolución social, podemos constatar que, en nuestro país, la materia ha tenido varias transformaciones.

Al tiempo de la codificación, la ley civil reconoció un solo modelo de familia. La codificación decimonónica reconoció en el Código Civil un modelo prácticamente único de familia, fundada en el matrimonio y en la sociedad conyugal, que otorgaba al marido preponderantes facultades económicas y personales sobre la mujer y los hijos. En la época, esto no constituyó ni un retroceso ni una innovación. En una sociedad de economía principalmente agrícola y doméstica ese era, en efecto, si bien no el único, el principal modelo de familia existente en el país. De esa forma, introdujo al derecho una respuesta conveniente para la realidad social de la época.

No obstante, tempranamente (iniciado el siglo XX), ciertas transformaciones sociales hicieron insuficiente dicha regulación. En particular, la mujer comenzó gradualmente a entrar al mercado laboral y, más adelante, mediante el control de la fertilidad, tal tendencia se fue acentuando. Fue así que la respuesta del derecho civil frente a esa evolución social fue gradual, y en cierta medida, provocó una deformación de las instituciones civiles. En efecto, la sociedad conyugal, que había sido concebida para un modelo familiar tradicional, donde la mujer tenía un rol vinculado al hogar y a los hijos, fue alterándose para dar cabida a otros modelos familiares, donde el trabajo asalariado se compartía entre los cónyuges. Fue por ello, que tempranamente en el siglo XX se le concedió el patrimonio reservado al interior de la sociedad conyugal, que le permitió administrar y gozar de aquellos bienes adquiridos con el fruto de su trabajo separado del marido. Más adelante, el mismo desarrollo de la economía y la progresiva complejidad de los negocios, hizo necesario que se permitiera a los cónyuges pactar la separación total de bienes.

Luego, varias restricciones se incorporaron a la administración del marido sobre los bienes sociales y los propios de la mujer, al interior de la sociedad conyugal. Por último, en la década de los 80 se eliminó -al menos formalmente- la incapacidad relativa de la mujer casada en sociedad conyugal.

El retorno a la democracia significó una renovación de la actividad legislativa en la materia y, valorando la igualdad al interior del matrimonio, se creó un nuevo régimen de bienes: la participación en los gananciales. Al mismo tiempo, se introdujo la institución de los bienes familiares, pues se detectó que, encontrándose 
separados de bienes, el patrimonio esencial de la familia estaba expuesto a enormes vicisitudes.

El resultado de esta evolución social y legislativa condujo a un estado de la ley civil que resulta confuso y preocupante, y que puede sintetizarse en ciertas características fundamentales.

Por una parte, existe el régimen de sociedad conyugal, el cual, en cierta medi$\mathrm{da}-\mathrm{y}$ producto de las múltiples transformaciones que se han mencionado-, fue "forzado" o "desfigurado", de tal forma de hacer entrar en él una administración parcial, paralela, ejercida por la mujer (mediante el patrimonio reservado).

El estado de este régimen de bienes es, simplemente, preocupante. Carga con el estigma de ser un régimen discriminatorio contra la mujer, y de constituir una regulación excesivamente restrictiva en términos de disposición patrimonial. Todo ello, explica que sea un régimen en progresivo y acelerado abandono, como lo muestran los hechos: desde el año 2006, se detecta una disminución de un promedio de $2 \%$ a $3 \%$ anual, de las parejas que se casan bajo ese régimen, y un aumento equivalente de aquellas que contraen matrimonio bajo el régimen de separación total de bienes. La constatación resulta alarmante, desde el momento en que la sociedad conyugal es el régimen que materializa la solidaridad familiar y de protección del patrimonio común (mediante los denominados haberes sociales), función que no se cumple con la separación de bienes.

En segundo lugar, nos encontramos con un régimen de separación total de bienes que va en aumento, que consiste en la negación a todo régimen patrimonial, de todo patrimonio común al interior de la familia y de solidaridad familiar entre sus integrantes.

En tercer lugar, el régimen de participación en los gananciales está en progresivo desuso, producto de su regulación poco adaptada al medio nacional. Actualmente, sólo el 2,35\% de las parejas se casan bajo ese régimen de bienes, porcentaje que se reduce cada año. Esto se debe a que la modalidad que se asignó a este régimen (crediticia), resulta excesivamente compleja, y muy poco adaptada para el medio jurídico nacional, acostumbrado a razonar en términos de comunidad.

\section{REFORMAS PENDIENTES Y MODELOS FAMILIARES}

Por tanto, la pregunta es: ¿qué se necesita en el presente en materia de reforma de regímenes patrimoniales del matrimonio?

Ante todo, pareciera indispensable preguntarse si resulta necesario reforzar la solidaridad familiar, esto es, la existencia de un mínimo de responsabilidad patrimonial compartida frente a las necesidades económicas de la familia. En el derecho comparado, esta cuestión se vincula a la discusión sobre la existencia del denominado "régimen primario". Puede estimarse que es un régimen de bienes primario, aquel que deriva de los deberes generales del matrimonio: socorro (derecho de alimentos) y asistencia a las necesidades del hogar común, esencialmente. 
En algunos sistemas, se incluye también una responsabilidad solidaria de los cónyuges frente a las deudas, para la subsistencia de la familia común (aplicable bajo cualquier régimen de bienes). Estos deberes existen siempre, con independencia del régimen de bienes que exista entre los cónyuges.

Estos deberes patrimoniales, y no personales, deben reforzarse y no desdibujarse. En efecto, constituyen el soporte económico esencial del matrimonio, que en ausencia de conflicto se aplica espontáneamente, sin necesidad de intervención judicial, conforme a la solidaridad familiar que naturalmente existe entre personas que han decidido formar una familia. En el conflicto, en cambio, tales deberes se ponen en acción mediante la intervención judicial, que puede establecer un derecho de alimentos o contribuciones para concurrir a los gastos de la familia común.

Lo que entendemos por regímenes de bienes, son en verdad secundarios, se aplican por sobre los deberes ya descritos, y constituyen en esencia una forma de regular las relaciones económicas entre cónyuges, que resulta particularmente relevante cuando el matrimonio termina por muerte o ruptura.

En segundo lugar, debemos preguntarnos si es necesario volver al matrimonio más atractivo, como forma de regulación de la vida en común.

En efecto, con prescindencia de las concepciones ideológicas que se tengan sobre el matrimonio, es innegable que la mayoría de las personas deciden vivir en pareja de forma permanente. A esas relaciones estables de pareja, el derecho privado debe entregar una regulación, adaptada a sus intereses, y adecuada para prevenir y solucionar conflictos.

Desde una perspectiva social, el contrato de matrimonio no es más que un instrumento legal, destinado precisamente a entregar a las parejas una regulación jurídica para su relación. El contrato de matrimonio, en términos jurídicos, tiene un papel trascendental en el quiebre matrimonial, durante el conflicto familiar. Es sabido que en la armonía familiar, el Derecho Civil tiene un papel casi inexistente. Es en el conflicto o en la tensión, en el quiebre o en la muerte, donde las personas resultan incapaces de resolver espontáneamente tales conflictos, y el derecho debe intervenir. En verdad, la causa del conflicto no es la convivencia, sino la congruencia de dos factores: la desavenencia y la propiedad. Es el surgimiento del patrimonio familiar construido por la pareja el que hace emerger la discordia (esencialmente en el quiebre sentimental), y la necesidad de que el derecho intervenga para proteger -comparativamente-, al más desvalido. La continuidad en el tiempo, la circunstancia que los proyectos compartidos se traduzcan en bienes adquiridos, hace emerger la necesidad del derecho. Así, durante la vida armoniosa de la pareja, bien poco puede contribuir el Derecho Civil. Dependiendo de las alternativas que se sigan para regular las relaciones patrimoniales, probablemente éste contribuye a clarificar, frente a terceros, si es necesario el consentimiento de ambos para la enajenación o gravamen de un bien adquirido durante la convivencia, o definir, frente a la muerte de uno de ellos, los derechos que le asistan al otro. 
De esta forma, durante la armonía familiar, el papel del contrato matrimonial es más bien limitado, y en tal etapa resulta importante también que los regímenes patrimoniales no se transformen en un obstáculo para la actuación de las personas en el mundo económico.

Pero en el quiebre familiar, la regulación matrimonial -particularmente, aquella que proviene del régimen patrimonial-cobra una importancia vital. Dependiendo del régimen elegido por los cónyuges, podrá ocurrir que ambos partan con la mitad de los bienes adquiridos en común (sociedad conyugal), que uno participe en las ganancias producidas por el otro (participación en los gananciales) o que simplemente cada cónyuge se lleve lo propio, sin compartirlo de forma alguna (separación total de bienes). Asimismo, en ese momento, resultará relevante si la dedicación preferente al hogar común y a los hijos de parte de un cónyuge hace procedente la denominada compensación económica.

De esta forma, la función de la regulación matrimonial (en particular, de los regímenes patrimoniales), es prevenir conflictos $y$, una vez generados, contribuir a resolverlos. Asimismo, la regulación pretende proteger patrimonialmente a los cónyuges y, en general, a la familia que han fundado. Y aunque existan concepciones ideológicas diversas, pareciera que existe consenso en que es un objetivo social deseable el que el Derecho pueda prevenir y resolver conflictos familiares, y proteger patrimonialmente a la familia.

Estas funciones sociales benéficas son ofrecidas por la ley a las parejas a través del matrimonio. Vemos que éste, en el presente, se encuentra en retroceso, esto es, un número creciente de parejas deciden compartir sus vidas sin suscribirlo. El número de matrimonios ha venido bajando en los últimos años, y las leves alzas que se experimentaron se deben, según algunos, únicamente al número de parejas que esperaban desde hace tiempo la formalización de la disolución de un vínculo anterior para contraer uno nuevo.

Expuesto lo anterior, cabe entonces la pregunta acerca de qué se ha hecho para volver al matrimonio una institución adaptada a las necesidades de las parejas.

En primer lugar, sin duda con la Nueva Ley de Matrimonio Civil (2004) se avanzó en materia de nuevas formas de constitución del vínculo, permitiendo que la ceremonia religiosa, celebrada por entidades que gocen de personalidad jurídica de Derecho Público, pudiera tener efectos civiles. Efectivamente, parece una prueba de pluralismo democrático y de respeto a la autonomía el que se entregue a las parejas la definición de la manera en que formalizarán su vínculo. Podemos afirmar, de esta forma, que esta medida va en el sentido de volver funcional el matrimonio a los propios proyectos familiares.

En segundo lugar, se avanzó sustantivamente, con esa misma ley, en materia de disolución del matrimonio, reconociendo expresamente el divorcio (desestimando al mismo tiempo el sistema de nulidades fraudulentas, que se practicaba masivamente como forma de divorcio desde la década de 1920), ampliando las causales de nulidad (para que aquellas personas cuyas creencias le impiden acceder 
al divorcio directamente, puedan de esta forma formalizar el término de su relación) y reconociendo la separación judicial, que también cumple un propósito similar a aquel que se tuvo en vista para ampliar las causales de nulidad.

La circunstancia de que hoy el matrimonio tenga formas reguladas de terminación, con mecanismos de protección de los hijos y del cónyuge débil, puede efectivamente presentarse como una reforma que vuelve más adaptado el matrimonio a las formas de pareja en el presente, en que efectivamente existe un importante número de ellas cuya convivencia se rompe con el tiempo.

El reconocimiento expreso del divorcio entrega una señal a las personas de que el Derecho contempla formas de disolución y de protección de la familia, cuestión que puede percibirse como una forma de incentivar su suscripción. En otros términos, el derecho señala a las personas que la posibilidad de equivocarse, de fracasar en el proyecto familiar -que es frecuente en la práctica-, está prevista y adecuadamente regulada, de forma que tengan menos dudas de formalizar su vínculo por medio del matrimonio.

En tercer lugar, se avanzó en materia de protección (de los hijos comunes y del cónyuge más débil) mediante la introducción de los bienes familiares y de la compensación económica. Como se expuso, estas figuras materializan uno de los principales objetivos de la regulación patrimonial del matrimonio (la protección de la familia común y del cónyuge que posterga la generación de ingresos para dedicarse a ella).

No obstante, quedan muchas cuestiones pendientes (reformas o adaptaciones del matrimonio), algunas generales y otras más específicas, de orden patrimonial (referidas precisamente a los regímenes de bienes del matrimonio).

Respecto de las cuestiones generales, no cabe aquí pronunciarse sobre ellas, pues son objeto de otras iniciativas legales. Ellas dicen relación, esencialmente, con la discusión de si es necesario abrir el matrimonio a las parejas homosexuales, o si es conveniente crear un contrato cercano, pero distinto al matrimonio (Acuerdo de Vida en Pareja). Estas cuestiones generales dicen relación también con ciertas correcciones necesarias a la regulación del divorcio, pues la práctica prueba que el denominado divorcio por culpa es utilizado en muy pocas oportunidades $y$, en tales casos, agrava los problemas familiares (en perjuicio, sobre todo, de los hijos). Lo anterior se vincula también con la constatación de que la nulidad (que, como se dijo, fue ampliada en causales en la reforma de 2004), no es utilizada en el presente, como tampoco lo es la separación judicial. En efecto, a pesar de que los ciudadanos se declaran mayoritariamente católicos, prefieren la sinceridad del divorcio y no la nulidad (aun cuando tal credo sólo acepta esta última como forma de disolución del matrimonio).

Más allá de tales cuestiones generales, las adaptaciones patrimoniales pendientes en el matrimonio, dicen directa relación con la materia de los Proyectos de ley en comento, como se expone a continuación.

Para determinar las adaptaciones patrimoniales pendientes en la regulación del matrimonio, deben efectuarse algunas anotaciones acerca de los modelos familia- 
res. Tal como se dijo al comienzo de esta exposición, la ley civil familiar es una regulación, que debe adaptarse a los modelos sociales de familia y, por ello, resulta relevante preguntarse cuáles son esos modelos en el presente.

Sobre la base de las estadísticas disponibles (esencialmente, el Censo 2002), puede sostenerse que existen dos modelos principales de familia. En efecto, se reconoce que la diversidad de las relaciones humanas es relativamente irreductible, pero existen ciertas formas típicas de ordenación de las relaciones de pareja, que suelen ser históricas y concurrentes.

Si se estima que sólo cerca de la mitad de las mujeres casadas trabaja, puede sostenerse que una parte importante de la población chilena, esencialmente aquella que vive en el campo, o que vive en las ciudades como trabajadores dependientes, tiene un estructura muy similar a aquella que inspiró la creación de la sociedad conyugal: un marido proveedor, frente a una madre dedicada principalmente a los hijos y al hogar común.

En este modelo podemos, naturalmente, encontrar varios matices. Un ejemplo es el caso en que la mujer ejerce, al mismo tiempo de ocuparse de los hijos y del hogar común, un trabajo remunerado a tiempo parcial (dependiente o independiente) para contribuir a la familia común. Otro ejemplo ocurre cuando los roles aparecen invertidos, pues un número no menor de hogares se encuentra a cargo de una mujer en Chile (no solamente monoparentales).

Un segundo modelo es el del matrimonio en que ambos cónyuges realizan trabajo remunerado a tiempo completo, y que se reparten las responsabilidades respecto de los hijos y del hogar, o encargan estas tareas a terceros (centros de educación y asistencia en el hogar).

Con el acceso cada vez más masivo de la mujer a las profesiones, este modelo va progresivamente aumentando su importancia relativa.

En este modelo existen también matices, como casos en que la mujer no renuncia a ocuparse del hogar y de los hijos, y efectúa al mismo tiempo una actividad remunerada, lo que le exige redoblar su esfuerzo, o postergar parcialmente, en el largo plazo, su desarrollo profesional. Otro matiz importante se produce cuando uno de los cónyuges, bajo este modelo de familia, cuenta con una fortuna propia anterior al matrimonio, que los cónyuges deciden, sin embargo, dejarla al margen de su comunidad de bienes.

Cabe hacer presente que existen en Chile, evidentemente, otras realidades familiares que, aunque con importancia en aumento, no corresponde analizarlas por diversas causas, como los casos de familias monoparentales (en que por razones obvias, no hay problemas de regímenes de bienes); familias recompuestas (que, en definitiva, sin perjuicio de aportar hijos de distintos matrimonios, se estructuran internamente sobre la base de uno de los dos modelos ya esbozados); uniones constituidas al margen del matrimonio (cuya situación patrimonial, sobre todo en caso de ruptura, es materia de otra discusión), etcétera. 
Luego, la pregunta consiste en definir qué modificaciones necesita la ley civil matrimonial para que su regulación patrimonial sea más adaptada a esos modelos. Para regular los dos modelos principales de familia descritos en el párrafo anterior, y sus respectivos matices, hay varias medidas que resultan aconsejables.

Para el primer modelo mencionado, pareciera que la sociedad conyugal (esto es, un régimen de comunidad de bienes actual) sigue siendo una respuesta adecuada a sus necesidades, por varias razones. En dicho modelo, por ejemplo, sigue siendo usual que el marido provea y administre, y que la mujer se dedique preferentemente al hogar, sin perjuicio que las decisiones relevantes (la residencia familiar) sean de consuno, como lo establece el propio estatuto legal.

La comunidad de bienes se presenta para este modelo familiar como un estatuto "protector". En principio, el patrimonio común da estabilidad económica a la familia, permite hacer frente a las necesidades de la familia común y contiene un tratamiento justo al término de la relación (división del patrimonio común en partes iguales).

Evidentemente, es necesario, según lo expuesto, ajustar este régimen a las exigencias del principio de igualdad y efectuar ciertas correcciones.

a) En primer lugar, establecer la administración separada e indistinta de cada cónyuge del patrimonio de la sociedad conyugal, salvo la ejecución de ciertas actuaciones, de mayor relevancia, donde se exija la actuación conjunta (gravamen o enajenación de bienes relevantes para la familia y otorgamiento de garantías). De esta forma, se supera la objeción de afectar el principio de igualdad, que atiende precisamente a que el marido es quien, en el presente, administra los bienes comunes y propios de los cónyuges.

b) En segundo lugar, se debe fortalecer $-y$ no debilitar- el patrimonio familiar, ya que éste constituye, como se dijo, fuente de estabilidad, de protección y de justicia para la familia. Esta cuestión, pasa por revisar tres instituciones: el patrimonio reservado de la mujer casada, los bienes que se consideren propios y los bienes que integren el patrimonio social.

El patrimonio reservado de la mujer casada pierde toda justificación, desde el momento en que ella misma pasa a administrar, con iguales poderes, los bienes comunes de la sociedad conyugal. En efecto, este patrimonio reservado, fue una manera de forzar la regulación de la sociedad conyugal, para hacer entrar en ella una nueva realidad social que emergía: el trabajo remunerado de la mujer (aunque fuere parcial). No resultaba justo que la mujer estuviera privada de toda injerencia en la administración de los bienes comunes, incluso los que ella misma contribuía directa o indirectamente a formar. La razón de esa institución se pierde cuando la ley le entrega iguales poderes de administración que al marido sobre los bienes comunes y bienes propios. Más aún, si se toma en consideración que un porcentaje importante de mujeres en nuestro país desarrolla actividad remunerada, pero en forma limitada, ya que, al mismo tiempo, dedica gran parte de su vida al hogar común y a los hijos. Resultará incluso más favorable para ella el administrar el pa- 
trimonio mayor (el de la sociedad conyugal), y no sólo el obtenido con su trabajo separado del marido.

Insistir en mantener este patrimonio reservado y, al mismo tiempo, entregarle la administración de la sociedad conyugal junto con el marido, provocará únicamente el nacimiento de una nueva discriminación, esta vez contra el marido, quien no tendrá ese privilegio, pues todo el producto de su trabajo entrará al patrimonio social.

Respecto de los bienes propios de cada cónyuge, constituidos esencialmente por bienes raíces heredados, queda también pendiente una reflexión, sobre todo porque los Proyectos pretenden -equivocadamente, en mi opinión- reforzar la autonomía en la administración y disposición respecto de los mismos. Ante todo, estos bienes tienen una gran importancia en la práctica (contrariamente a lo que sostienen algunos), pues con las políticas de subsidios habitacionales, existe un número masivo y creciente de ciudadanos que acceden a la propiedad del inmueble que habitan, y que termina siendo la principal herencia que dejan a sus descendientes. $\mathrm{Al}$ mismo tiempo, existe por ello un número importante de familias que ocupa como residencia principal un bien que ha sido heredado por uno de los cónyuges. Ahora bien, si es tan frecuente, importante, y son los mismos cónyuges quienes han optado por acceder a este régimen patrimonial de comunidad, ¿̇se justifica que la ley trate a estos bienes como propios, y que pueda cada uno administrarlos y disponerlos libremente? ¿Acaso eso no implica una medida de desprotección de la familia común?

El matrimonio obliga a los cónyuges a asistirse y socorrerse en circunstancias de necesidad (pobreza, enfermedad, accidentes, etcétera). ¿Por qué, si la ley les obliga a apoyarse frente a las desgracias, no los obliga -al mismo tiempo- a compartir los frutos de las circunstancias afortunadas que puedan sobrevenir? Si los cónyuges decidieron vivir juntos y poner su patrimonio en común, ¿por qué la ley debería negar ese carácter a un bien tan importante como el inmueble heredado? En opinión de este académico, todo indica que tales bienes deberían seguir la suerte del patrimonio común, sobre todo, si ambos tendrán iguales poderes de administración sobre tales bienes.

La solución no es tan alejada de la que existe en el presente, pues para la enajenación de los bienes propios de la mujer se exige la voluntad del marido. ¿Por qué no hacer esta regla recíproca, de manera de fortalecer y no debilitar el patrimonio familiar?

Por último, la situación de los haberes de la sociedad conyugal debe revisarse, también en pos de fortalecerlos, en beneficio del patrimonio común familiar. Por ello, no parece razonable la medida propuesta por el Mensaje, como se expone más adelante, que transforma el haber relativo de la sociedad conyugal en bienes propios.

c) En tercer lugar, cabe la pregunta de si este modelo familiar merece también la protección reforzada de los bienes familiares. La respuesta dependerá de cuán fuerte se haga el patrimonio común de la sociedad conyugal: mientras más fuerte sea, 
menos protección se requiere mediante la institución de los bienes familiares (que ha venido, en parte, a suplir la desprotección en que se deja a la familia cuando los bienes importantes para ella son propios de cada cónyuge). En todo caso, tal como en materia de sociedad conyugal, deben revisarse cuáles son los bienes relevantes para la familia, respecto de los que se exigirá actuación conjunta (¿`ólo el inmueble, o también otros bienes como el automóvil o la participación en sociedades?). También, en materia de bienes familiares, se requiere una revisión de los tipos de bienes susceptibles de declararse como tales, su forma de constitución y publicidad. Eso era lo que se proponía en el proyecto contenido en el Boletín No 1707-18, en una modificación aprobada por la Cámara de Diputados, según se expuso.

d) Por último, cabe la pregunta de si en este modelo familiar merece una nueva protección el denominado "cónyuge débil", como parece proponerlo el Mensaje. En opinión de este académico, la institución de los bienes familiares y la compensación económica son instrumentos suficientes para cumplir esa función, sin perjuicio que puedan perfeccionarse, como ya he expuesto.

Para el segundo modelo de familia mencionado, formado por un matrimonio en que ambos cónyuges realizan trabajo remunerado a tiempo completo, un régimen de participación en los gananciales parece adecuado. En efecto, el espíritu de este régimen es otorgar a los contrayentes la libre administración de todos sus bienes durante la vigencia del matrimonio. Para este modelo, la participación en los gananciales puede ser una figura atractiva y más solidaria que la simple separación de bienes, por cuanto envuelve el compromiso de repartir por mitades lo adquirido durante el matrimonio al término de éste (por muerte o ruptura). El gran problema en el presente, es que la forma en que está regulado en la ley (modalidad crediticia) lo vuelve un régimen técnicamente muy complejo, y por ello en desuso, cuestión que se podría resolver de manera bastante simple, cambiando esa modalidad por la de "comunidad final".

Es posible suponer que esta misma circunstancia -lo complejo de su implementación- ha impulsado a muchas parejas a desechar este régimen y optar por la separación de bienes, pues aun cuando estén de acuerdo con la justicia de ese reparto final, su suscripción y puesta en práctica presenta un alto grado de complejidad.

Por último, ya se dijo que la separación total de bienes en realidad es la negación de todo régimen patrimonial, y, por ello, es poco protectora para la familia, e injusta en el quiebre familiar. Para paliar estas consecuencias negativas, conviene reforzar la protección mediante el denominado régimen primario, y las modificaciones enunciadas a los bienes familiares (cuya existencia se justifica también por el aumento, precisamente, de las separaciones de bienes, que no dejan de crecer porcentualmente).

\section{Pertinencia de los cambios propuestos por los Proyectos}

A continuación, corresponde preguntarse si los proyectos en comento, en particular el contenido en el Mensaje (Boletín No 7567-07), efectúan estas adecuaciones 
necesarias del matrimonio, con el fin de fortalecer la solidaridad familiar, e instar a la prevención y resolución de sus conflictos, transformándolo nuevamente en una regulación atractiva y pertinente para las relaciones de pareja.

En opinión de este académico, lamentablemente no lo consigue, por varias razones.

(i) En primer lugar, no se entrega ninguna solución jurídica para el segundo modelo familiar descrito, en el que ambos cónyuges trabajan, que progresivamente va aumentando en nuestro país, para los que es urgente la existencia de un régimen de comunidad diferida apropiado. Estos cónyuges no cuentan en el presente con un régimen patrimonial adaptado a sus intereses, que entregue soluciones justas al término de la relación (que es cuando -ya lo he mencionado- resultan particularmente relevantes los regímenes patrimoniales). Los cónyuges necesitan administrar plena y libremente lo que consiguen con su trabajo, pero estarían dispuestos a compartir las ganancias si la vida en común fracasa por alguna circunstancia. No obstante ello, el régimen de participación en los gananciales, por la modalidad en que fue adaptado en nuestro país (crediticia), se presenta como un mecanismo técnico complejo, que no se aviene con las costumbres nacionales, todo lo cual conduce a que su puesta en práctica sea excesivamente complicada, cuestión que explica por qué, prácticamente, es una ley en desuso.

Estas parejas, en consecuencia, sólo tienen acceso en el presente a la separación total de bienes, en atención a que la sociedad conyugal se presenta como un régimen poco adaptado para quienes necesitan administrar libremente su patrimonio, por razones profesionales o comerciales. Pero, como he señalado, la separación total de bienes es la negación del régimen patrimonial del matrimonio, y envuelve una solución final poco consistente con la realidad de dos personas que decidieron construir un proyecto familiar común y que lo mantuvieron en el tiempo (que puede ser considerable).

(ii) En segundo lugar, los Proyectos tampoco mejoran la situación del denominado régimen primario, que constituye un mínimo común de obligaciones patrimoniales de los cónyuges, en beneficio de la familia común, que existe con independencia del régimen patrimonial que elijan. Existen razones, anteriormente expuestas, que conducen a sostener que tales deberes deben fortalecerse y no debilitarse, como forma de contrarrestar la desprotección que envuelve el aumento sostenido del régimen de separación total de bienes.

(iii) En tercer lugar, los Proyectos olvidan también las reformas que ya se habían estudiado durante trece años, aprobadas en esta misma Cámara de Diputados (Boletín No 1707-18), que mejoraban los procedimientos de constitución, de publicidad, y ampliaban el catálogo de bienes que pueden ser objeto de la declaración de bien familiar, además de introducir varios elementos que perfeccionaban la institución, sobre los cuales existía unanimidad. Si bien hay algunos proyectos en curso que abordan algunos de esos aspectos (Boletines $\mathrm{No}^{\circ}$. 6889-07 y 782507; los otros están archivados), ninguno de ellos asume de manera integral tales 
correcciones, como sí lo hacía el mencionado proyecto, contenido en el Boletín No 1707-18. Este académico lamenta, nuevamente, que todo ese trabajo legislativo y académico, realizado durante trece años, se haya desechado, pues entre otras consideraciones, pareciera del todo necesario asegurar una continuidad en el debate legislativo de las reformas, aprovechando las contribuciones y consensos académicos que se alcanzaron en procesos anteriores.

(iv) En cuarto lugar, los Proyectos, y en particular el Mensaje, no eliminan la desigualdad de la mujer casada en sociedad conyugal. En efecto, existen varias razones que conducen a la conclusión de que la fórmula propuesta en estos Proyectos no conducirá a asegurar la igualdad de la mujer en el régimen de sociedad conyugal.

Los proyectos establecen una administración alternativa, entregada a la voluntad de los cónyuges, esto es, que deberán ser ellos quienes designen la persona del cónyuge administrador. Una medida de esa naturaleza convierte la igualdad dentro de la sociedad conyugal en una ficción, por las siguientes razones:

a) Porque es evidente que la solución pasa por obligar a los cónyuges a decidir quién de ellos tendrá una situación preeminente o superior en el matrimonio. Los obliga a elegir quién deberá subordinar sus propias decisiones a las decisiones del otro. En otros términos, más que asegurar la igualdad, esta regla los obliga a tomar una decisión que en sí misma resulta discriminatoria: elegir cuál de ellos tendrá el poder de decidir.

b) También resulta ilógico pretender que la solución a la situación de desigualdad al interior del matrimonio pueda resolverse entregándoles la libre decisión de la administración a los cónyuges, entregándoles a ellos mismos la tarea de superar la desigualdad. Es evidente que tal medida conducirá, en amplios sectores de la población, a mantener el estado de cosas, y a reproducir el esquema de administración tradicional por parte del marido.

c) Lo anterior arroja una solución que no resuelve el problema, y que introduce un factor inicial de discordia y tensión entre los cónyuges. Piénsese, en efecto, en la dificultad que reviste para las parejas tener que consensuar quién de ellos deberá renunciar a sus facultades de administración del patrimonio común en beneficio del otro, quién tendrá una posición preponderante y el control sobre el otro.

d) Además, los Proyectos, y en particular el Mensaje, introducen fuertes e inaceptables incentivos para que los cónyuges elijan al marido como administrador de la sociedad conyugal, manteniendo el estado actual de cosas. Así, por ejemplo, a la mujer se le entrega el derecho a formar un patrimonio reservado para administrar lo que consigue con su trabajo, en caso que el marido sea elegido como administrador. Pero, a la inversa, si la mujer es elegida administradora, el marido no tendrá derecho a administrar en forma alguna lo que obtenga con su trabajo, pues no se reconoce en su favor un patrimonio reservado.

En el mismo sentido, el Mensaje (al menos en su redacción original, que después fue modificada por la Comisión de Familia), le otorgaba a la mujer que fuera 
nombrada administradora de la sociedad conyugal, y que tuviera una dedicación preferente al hogar común y a los hijos, una especie de segunda compensación económica, impidiendo que el marido pueda renunciar a los gananciales para conservar su patrimonio reservado (en el Mensaje original también se le atribuía al marido la posibilidad de formar un patrimonio reservado). La existencia de esta segunda compensación económica, envolvía nuevamente un incentivo para nombrar administrador al marido, y evitar así estar obligado a esta nueva prestación.

En gran medida, varias de las modificaciones que plantea el Mensaje, dejan la impresión que en él subyace una fuerte consideración paternalista, y un estímulo a que la mujer conserve un rol doméstico y familiar. Todos los incentivos económicos descritos conducen a una posición en que a la mujer, al interior de la sociedad conyugal, se le entregue un tratamiento preferencial si decide ceder la administración al marido y dedicarse a los hijos. La prueba más evidente de lo anterior, es que si desarrolla un trabajo remunerado, se perdía el derecho a esta segunda compensación económica.

e) Por último, es cierto que los Proyectos establecen la posibilidad de una administración conjunta de la sociedad conyugal, pero su regulación es sumamente equívoca: no se sabe si dicha administración puede decidirse durante el matrimonio (y no sólo al principio); no es claro cómo operaría en la práctica esta administración conjunta, en particular, cómo se resolverían los conflictos que se susciten al interior de la administración. Los Proyectos proponen que, salvo ciertos actos, respecto de todos los restantes se presuma que se cuenta con la autorización del otro cónyuge, abriendo una puerta amplia a la litigación, para efectos de desestimar tal presunción. Así, pareciera que esta administración conjunta se menciona, pero no se regula adecuadamente. Además, una administración conjunta para todos los actos y contratos que puedan celebrarse durante la vigencia del régimen, parece una medida excesivamente burocrática, que cercena brutalmente la libertad de los cónyuges, y que introduce nuevas causas de desavenencia al interior del matrimonio. Es por ello, como se ha expuesto, que parece preferible optar por una administración separada e indistinta, sujeta a ciertos correctivos en razón de actuaciones relevantes, que requieran la actuación conjunta, o al menos la autorización previa del otro cónyuge para surtir efectos civiles.

(v) En quinto lugar, y en una nueva muestra de paternalismo, los Proyectos insisten en fijar un régimen supletorio, aplicable en silencio de los cónyuges (el de sociedad conyugal).

Desde el punto de vista de la igualdad, es preferible que el legislador no establezca un régimen legal supletorio, sino que se inste a los contrayentes a decidir qué régimen de bienes se ajusta mejor a su proyecto de vida común. De esta forma, se estimula a los contrayentes, en ausencia de cualquier "modelo sugerido", a determinar libremente el sistema de regulación patrimonial que consideran más justo. Todos los regímenes de bienes del matrimonio pueden explicarse, en su esencia, en términos muy simples, y su elección es una decisión tan trascendental 
en la vida de las personas, que no parece ser válida la objeción de que los contrayentes no podrían llegar a percibir su alcance. Si las personas tienen capacidad para comprender y comprometerse al matrimonio, ¿cómo puede sostenerse que no la tendrían para decidir sobre la constitución patrimonial de su familia? Si en el derecho contemporáneo se obliga a las personas a informarse acabadamente respecto de cualquier acto de consumo antes de su suscripción, cómo no estimular el conocimiento de las personas, para la adopción de una decisión consciente respecto del que, probablemente, será el principal contrato patrimonial que suscribirán en sus vidas (la elección del régimen de bienes).

Por lo demás, la creación de un régimen supletorio conduce a preguntarse cuál de ellos debería tener este carácter. Si se opta por el que representa el modelo familiar mayoritario, existen dudas de que sea el de sociedad conyugal (fundado en una estructura en que sólo el marido trabaja), pues es sabido que la mujer ha entrado masivamente al mercado laboral desde hace mucho tiempo. Si se insiste en mantener como supletoria a la sociedad conyugal, ¿̇acaso no se está, implícitamente, incentivando un esquema familiar en que la mujer deba mantener un rol doméstico y familiar? Como se ha expuesto, esa no es la función de las leyes civiles.

(vi) En sexto lugar, las normas del Proyecto debilitan la solidaridad familiar. Las normas propuestas mantienen la existencia del patrimonio reservado, se mantiene la existencia de los bienes propios e, incluso, los bienes que antes pertenecían al haber relativo de la sociedad conyugal, pasan a ser bienes propios (lo que sin duda tiene importancia, por tratarse de los bienes muebles que aportan los cónyuges al matrimonio o que adquieren a título gratuito).

De esta forma, cabe preguntarse si en realidad estamos hablando de un régimen de comunidad, ya que muy pocos bienes formarían parte del patrimonio familiar.

Por una parte, se mencionó que el único fin del patrimonio reservado fue entregar a la mujer una esfera de administración separada, justificación que se diluye cuando se abre la administración de la sociedad conyugal también para ella. Por otra parte, si es discutible la existencia misma de bienes "propios" en un régimen en que los cónyuges han optado por la comunidad, más cuestionable aún es que se pretenda acrecentar esos bienes propios (mediante el haber relativo), debilitando aún más el patrimonio familiar. De esta forma, en realidad se está cerca de crear un nuevo régimen patrimonial de cuasi separación de bienes, o de comunidad severamente restringida.

En definitiva, estas propuestas terminan por debilitar el patrimonio común, que sirve de sostén a la familia, y ya se expusieron las consecuencias sociales negativas de proceder de esta forma.

(vii) En séptimo lugar, las modificaciones propuestas (al menos en su actual redacción) crean una nueva discriminación, esta vez, en perjuicio del marido, pues sólo la mujer no administradora tendrá derecho a formar y administrar un patrimonio reservado. Lo anterior merece serios reparos. Ante todo, la propuesta 
crea una nueva desigualdad de género, ya que la discriminación ahora se extiende al marido que no tenga la administración de los bienes sociales, al privársele del beneficio del patrimonio reservado. Luego, teniendo la mujer la posibilidad de administrar la sociedad conyugal, no tiene sentido mantener una institución pensada precisamente para la situación contraria, es decir, aquella en que la mujer no puede directamente intervenir en la administración de los bienes de la sociedad. Por otra parte, y según ya se ha expuesto, esta decisión debilita la solidaridad familiar, al privar a la comunidad de esos bienes. Una decisión legislativa coherente debiese optar por una de dos alternativas: o reconoce el patrimonio reservado para el cónyuge administrador, sin distinción, o simplemente lo elimina (como se dijo, esta última opción parece la más aconsejable).

(viii) Asimismo, en materia de límites a las facultades del cónyuge administrador de la sociedad conyugal, los Proyectos (en particular, el Mensaje) no innovan, manteniendo la regla de que sólo se refiere a los bienes raíces, excluyendo otros bienes importantes. En efecto, se mantiene la regla de que el cónyuge no administrador no podrá enajenar o gravar voluntariamente, ni prometer enajenar o gravar los bienes raíces sociales sin autorización del otro. De esta forma, se mantienen las deficiencias de la regulación actual en relación a la protección del cónyuge no administrador, pues no hay regla alguna que limite la enajenación o gravamen de bienes muebles valiosos del haber social, los que constituyen, en numerosos casos, aquellos que representan la mayor parte del patrimonio social.

(ix) Por último, los Proyectos introducen nuevos riesgos en la regulación. Entre los más importantes se cuenta la autorización para pactar la sociedad conyugal durante el matrimonio, contrariando la regla de que en materia de matrimonio -y para evitar el fraude a terceros- no se puede pasar de un régimen no comunitario a uno de comunidad actual. Asimismo, en el caso de administración extraordinaria, se decide excluir la intervención del juez para autorizar los actos que, en administración ordinaria, requieren la autorización del otro cónyuge (agregando una acción de indemnización de perjuicios para el caso de utilización de mala fe de esta facultad), abriendo de esta forma una nueva puerta para afectar la integridad del patrimonio de familia e incentivar la litigación al interior de ésta (mediante la acción de indemnización de perjuicios proveniente del Derecho Civil patrimonial).

\section{REFLEXIONES FINALES}

Resulta indiscutible que los regímenes patrimoniales requieren una reforma importante en el derecho nacional, y que, en opinión de este informante, los Proyectos comentados no van en la dirección correcta.

Para enfrentar una reforma de esta naturaleza, nos parece adecuado incluir algunas modificaciones, que sintetizamos a continuación:

(i) Orientar la modificación de la administración de la sociedad conyugal a favor del principio de igualdad, fijando una administración indistinta y separada 
de cada cónyuge, y sujetándolos a una actuación conjunta respecto de un catálogo de actuaciones relevantes (catálogo que debe ser ampliado).

(ii) Fortalecer -y no debilitar- el patrimonio común de la sociedad, manteniendo el haber relativo (o transformándolo en absoluto), y reflexionando sobre la pertinencia de mantener los bienes propios de administración separada con poderes ilimitados.

(iii) Reformar el régimen de participación en los gananciales, modificando su modalidad por uno de comunidad diferida, con el objeto de transformarlo en un instrumento útil para regular patrimonialmente aquel modelo familiar en que ambos cónyuges trabajan.

(iv) Fortalecer el régimen primario, para que opere en beneficio de la mantención de la familia común, con independencia del régimen de bienes por el que opten los cónyuges.

(v) Modificar la forma de constitución y los bienes susceptibles de declararse como familiares.

Finalmente, debemos insistir en que se debe tener presente que una buena parte de estas medidas fueron latamente estudiadas, llegándose a varios consensos, en el proyecto contenido en el Boletín No 1707-18, actualmente en segundo trámite constitucional. Una continuidad en el debate legislativo, y en las discusiones y contribuciones doctrinales que lo inspiraron, aconsejan retomar esa iniciativa. 